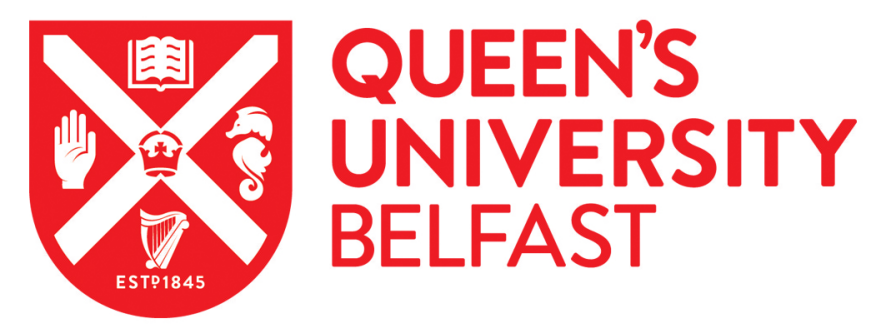

\title{
Modelling the intradermal delivery of microneedle array patches for long-acting antiretrovirals using PBPK
}

Rajoli, R. K. R., Flexner, C., Chiong, J., Owen, A., Donnelly, R. F., Larrañeta, E., \& Siccardi, M. (2019).

Modelling the intradermal delivery of microneedle array patches for long-acting antiretrovirals using PBPK. European Journal of Pharmaceutics and Biopharmaceutics. https://doi.org/10.1016/j.ejpb.2019.09.011

\section{Published in:}

European Journal of Pharmaceutics and Biopharmaceutics

\section{Document Version:}

Peer reviewed version

Queen's University Belfast - Research Portal:

Link to publication record in Queen's University Belfast Research Portal

\section{Publisher rights}

Copyright 2019 Elsevier

This manuscript is distributed under a Creative Commons Attribution-NonCommercial-NoDerivs License

(https://creativecommons.org/licenses/by-nc-nd/4.0/), which permits distribution and reproduction for non-commercial purposes, provided the author and source are cited.

\section{General rights}

Copyright for the publications made accessible via the Queen's University Belfast Research Portal is retained by the author(s) and / or other copyright owners and it is a condition of accessing these publications that users recognise and abide by the legal requirements associated with these rights.

Take down policy

The Research Portal is Queen's institutional repository that provides access to Queen's research output. Every effort has been made to ensure that content in the Research Portal does not infringe any person's rights, or applicable UK laws. If you discover content in the Research Portal that you believe breaches copyright or violates any law, please contact openaccess@qub.ac.uk. 


\section{Journal Pre-proofs}

Research paper

Inpepean

loupial of

Pharmaceuties and

i) iophapmacentios

Modelling the intradermal delivery of microneedle array patches for long-acting antiretrovirals using PBPK

Rajith K.R Rajoli, Charles Flexner, Justin Chiong, Andrew Owen, Ryan F. Donnelly, Eneko Larrañeta, Marco Siccardi

PII:

S0939-6411(19)30545-4

DOI: https://doi.org/10.1016/j.ejpb.2019.09.011

Reference:

EJPB 13151

To appear in:

European Journal of Pharmaceutics and Biopharmaceutics

Received Date:

9 May 2019

Revised Date:

1 August 2019

Accepted Date:

Please cite this article as: R. K.R Rajoli, C. Flexner, J. Chiong, A. Owen, R.F. Donnelly, E. Larrañeta, M. Siccardi, Modelling the intradermal delivery of microneedle array patches for long-acting antiretrovirals using PBPK, European Journal of Pharmaceutics and Biopharmaceutics (2019), doi: https://doi.org/10.1016/j.ejpb.2019.09.011

This is a PDF file of an article that has undergone enhancements after acceptance, such as the addition of a cover page and metadata, and formatting for readability, but it is not yet the definitive version of record. This version will undergo additional copyediting, typesetting and review before it is published in its final form, but we are providing this version to give early visibility of the article. Please note that, during the production process, errors may be discovered which could affect the content, and all legal disclaimers that apply to the journal pertain.

(C) 2019 Published by Elsevier B.V. 


\title{
Modelling the intradermal delivery of microneedle array
}

\section{patches for long-acting antiretrovirals using PBPK}

\author{
Rajith KR Rajoli ${ }^{1 *}$, Charles Flexner $^{2}$, Justin Chiong ${ }^{1}$, Andrew Owen ${ }^{1}$, Ryan F \\ Donnelly $^{3}$, Eneko Larrañeta ${ }^{3}$, Marco Siccardi $^{*}$
}

${ }^{1}$ Department of Molecular and Clinical Pharmacology, University of Liverpool, Liverpool, UK

2 Johns Hopkins University School of Medicine and Bloomberg School of Public Health, Baltimore, MD, USA

${ }^{3}$ School of Pharmacy, Queen's University Belfast, Medical Biology Centre, Belfast, UK

*Authors for correspondence: Dr Rajith KR Rajoli \& Dr Marco Siccardi, Department of Molecular and Clinical Pharmacology, University of Liverpool, 70 Pembroke Place, Liverpool, L69 3GF, U.K.

Tel No +44 (0) 1517945911

E-mail: rkrajoli@liverpool.ac.uk, siccardi@liverpool.ac.uk

Running Title: PBPK modelling of intradermal microneedle array patches

Key words: PBPK, intradermal, microneedle, patch, antiretroviral, long-acting 


\section{Abstract}

Introduction: Existing HIV therapy using oral antiretrovirals (ARVs) can result in pill fatigue and sub-optimal adherence. Microneedle array patches (MAPs) offer non-invasive, blood-free and painless drug delivery, and may improve patient adherence. The objective of this study was to develop a novel physiologically-based pharmacokinetic (PBPK) model to simulate the systemic pharmacokinetics of cabotegravir and rilpivirine MAPs using the intradermal route.

Methods: The developed PBPK models were qualified against observed pharmacokinetic data after intramuscular (IM) and intradermal administration of long-acting nanoformulated rilpivirine to rats, and for IM administration of both drugs to healthy adults. Qualified models were then utilised to estimate suitable MAP characteristics (e.g. nanoformulation dose and release rates) and inform dosing strategies to maintain plasma concentrations above target trough concentrations for the designated dosing interval.

Results: PBPK models simulated q4-weekly loading and maintenance doses of $360 \mathrm{mg}$ and $180 \mathrm{mg}$ for long-acting formulated cabotegravir between the release rates of $1 \times 10^{-3}-3 \times 10^{-3}$ $\mathrm{h}^{-1}$ and $1 \times 10^{-3}-1.5 \times 10^{-3} \mathrm{~h}^{-1}$ respectively, for a $70 \mathrm{~kg}$ adult. Estimated patch size was $60 \mathrm{~cm}^{2}$ for a $360 \mathrm{mg}$ dose of cabotegravir. For q4-weekly dosing, rilpivirine required a $1080 \mathrm{mg}$ loading dose and a $540 \mathrm{mg}$ maintenance dose with release rates of $1.5 \times 10^{-3}-2.5 \times 10^{-3} \mathrm{~h}^{-1}$ and $5 \times 10^{-4}-1 \times 10^{-3} \mathrm{~h}^{-1}$, respectively. Weekly dosing was also evaluated to assess the potential application from a smaller patch size. The ability to self-administer via a patch that is only left in place for a short duration makes longer durations less important than for some other long-acting approaches. Weekly cabotegravir required $60 \mathrm{mg}$ between release rates $7 \times 10^{-3}-$ $9 \times 10^{-3} \mathrm{~h}^{-1}$ and rilpivirine required $270 \mathrm{mg}$ and $180 \mathrm{mg}$ respectively between release rates of $7 \times 10^{-3}-9 \times 10^{-3} \mathrm{~h}^{-1}$ 
Discussion: This model estimated optimal dose and release rates for cabotegravir and rilpivirine MAPs. Our approach provides a computational platform to support rational development of intradermal administration strategies to tackle problems associated with chronic oral ARV administration. 


\section{Introduction}

Antiretrovirals (ARVs) have improved the average lifespan of infected individuals and also found clinical application in HIV pre-exposure prophylaxis (PrEP), preventing transmission to high risk individuals. The majority of existing ARVs are available only as oral formulations. They require daily administration and chronic dosing, often resulting in suboptimal adherence and pill fatigue $(1,2)$. Alternative dosing strategies such as long-acting injectables (LAIs) have been utilised for the administration of antipsychotics (e.g. paliperidone palmitate) and contraceptives (e.g. medroxyprogesterone), effectively addressing adherence issues associated with chronic oral administration (3). The recent development of cabotegravir and rilpivirine LAI intramuscular (IM) nanoformulations has stimulated interest in this strategy (4).

The existing injectable ARV formulations face challenges that may hinder development, acceptability, and widespread implementation although they have proven very successful for other indications. Administration of IM injections typically requires a skilled healthcare worker. For LAI rilpivirine, two large volume injections are necessary and the formulation requires a cold-chain, thus hindering clinical implementation (5). Importantly, cold chain is required because of stability of an excipient rather than the drug itself and thus this may not be a widespread problem for the approach. Nonetheless, the need for cold chain increases cost and, in low income countries, may reduce or even prevent access to treatments. In addition, some studies noted that $20 \%$ of people administered with IM injection reportedly suffer from needle phobia. This may reduce the number of patients accepting injectables, as seen for vaccines and routine dental procedures (6). It should be noted that all existing HIV patient attitude surveys for LAI approaches have shown a high level of enthusiasm for the approach, but complimentary approaches warrant further investigation (7-9). 
Microneedle array patches (MAPs) can be used for minimally-invasive intradermal delivery of micro- or nanoformulated drug into the skin (10). The intradermal route of administration has multiple advantages compared to oral intake, avoiding gastrointestinal degradation and first-pass metabolism, resulting in reduced total dose and may improve patient adherence (11). MAPs disrupt the stratum corneum, the major skin barrier to drug delivery, and can deliver drugs painlessly and without drawing blood into the upper skin layers (12), thus avoiding local pain, bruising, discomfort or bleeding (13). Drugs deposited in particulate form by MAPs in viable skin layers can be absorbed systemically by the rich dermal microcirculation upon release into the interstitial fluid (13). Hence, MAPs represent a promising strategy for chronic administration as long as the doses necessary for adequate pharmacokinetic exposure can be achieved, and may be compatible with nanoformulation strategies being investigated for long-acting drug delivery $(14,15)$.

Various types of MAPs exist for intradermal drug delivery (e.g. hollow, dissolvable and solid) and these have been extensively studied in the delivery of various drugs, including large molecules and vaccines. Hollow stainless steel microneedles (AdminPen ${ }^{\circledR}$ template) $^{-}$ have been used to deliver liquid formulations (16). MAPs can be used for the delivery of biomacromolecules (17), transcutaneous immunization (18) and hormones (19).

Polymeric MAPs are suitable for LA systemic delivery of small molecules. Hydrogelforming MAPs control drug release through in-skin hydrogel swelling (20). Micro- or nanoformulations loaded into dissolving MAPs deliver the formulations to the viable skin layers upon dissolution of the needles. Subsequent controlled drug release from the polymeric micro- or nanoparticles can then achieve LA release for sustained time intervals $(21,22)$. Unlike hydrogel-forming MAPs, drug release is therefore possible for weeks or even months after removal of the patch, thus potentially improving patient compliance. 
Preclinical and clinical evaluation of novel formulations and modes of delivery is hindered by numerous challenges. Computational simulations can support design of successful administration strategies and rational optimisation. Physiologically-based pharmacokinetic (PBPK) modelling is based on the mathematical description of anatomical, physiological and molecular processes describing pharmacokinetics through the integration of drug and patient specific data (23). PBPK modelling has been increasingly used in new chemical entity (NCE) applications and in investigation of clinical scenarios, suggesting reliability in pharmacokinetic predictions. PBPK models have been used to inform drug-drug interactions, CYP induction/ inhibition, pharmacogenetics and therapy optimisation in special patient populations (24).

The aim of this paper was to develop a novel intradermal PBPK model for ARV administration using MAPs. The developed model was used to identify minimum dose and a range of release rates for the LA administration of cabotegravir and rilpivirine nanoformulations to maintain plasma concentrations above established antiretroviral targets throughout dosing intervals of one to four weeks. 


\section{Methods}

A whole-body PBPK model was used to assess the intradermal release from MAPs in healthy adults. An intradermal compartment was appended to an earlier PBPK model using Simbiology ${ }^{\circledR}$ v.4.3.1., a product of MATLAB $^{\circledR}$ v.8.2 (MathWorks, Natick, MA, USA 2013) (25) Drug distribution was described using blood flow-limited, first-order kinetics (26). Instant and uniform drug distribution across each tissue and organ was assumed. Ethical approval was not required for this study as the data was computer generated.

\section{Microneedle patch}

In this exploratory study, we used a single dissolving MAP design as a starting point, based on some of our previous work (27). The thickness of stratum corneum, viable epidermis and dermis were in the range of $12-20 \mu \mathrm{m}(28), 50-80 \mu \mathrm{m}$ (29) and 300-4000 $\mu \mathrm{m}$ (30) respectively. An $11 \times 11$ array of microneedles $600 \mu \mathrm{m}$ long with an interspacing of $300 \mu \mathrm{m}$ on a $0.49 \mathrm{~cm}^{2}$ baseplate were considered as the base of a single microneedle array (27). A mean penetration depth of the microneedles after skin application was assumed to be $430 \pm$ $6.0 \mu \mathrm{m}$, with a pore width of $224 \pm 5.0 \mu \mathrm{m}$ made during penetration for each microneedle (27). A maximum of $32.7 \mathrm{mg}$ formulation (including drug and excipients) was assumed per MAP (made up of 16.33 individual microneedle arrays), with an area of $8 \mathrm{~cm}^{2}$. An average of $3.55 \mathrm{ml} / \mathrm{min} / 100 \mathrm{~g}$ tissue $\left(2.8-4.3 \mathrm{ml} / \mathrm{min} / 100 \mathrm{~g}\right.$ tissue) $(31)$ and $8 \times 10^{-6} \mathrm{~cm}^{3} / \mathrm{s} / \mathrm{cm}^{3}$ of tissue (31) in the adult forearm were considered as the respective blood and lymphatic flow rates to the intradermal compartment.

\section{Intradermal PBPK model}

The intradermal compartment was adapted and modified from Gajewska et al. (32), as shown in Figure 1. The intradermal compartment has been divided into four sub-compartments, namely stratum corneum, viable epidermis, hair follicles and dermis. The inserted 
microneedle was divided into three different compartments having a relative proportion of the total drug amount depending on insertion length and pore width of each skin layer as shown in Figure 2.

The following assumptions were made in the skin compartment: 1) unidirectional drug flow from the top layer (stratum corneum) to blood circulation; 2 ) hair follicles cover $0.1 \%$ of the total skin (as previously described, it was assumed that hair follicles have access to one-third of the drug traversing laterally, with one-fourth of the fine skin's blood-flow reaching the hair follicles (32)); 3) diffusion and partition coefficients across different skin layers and nanoparticle release rate were kept constant throughout the kinetic process; 4) only the free drug released from the nanoparticles diffuse through the layers of skin to reach blood circulation. Drug flow through the intradermal compartment is shown in Figure 2. The equations used in the intradermal compartment are as follows:

Drug present at the microneedle depot in the stratum corneum:

$$
\begin{gathered}
\frac{d D_{S C}}{d t}=-2 \times K_{T D} \cdot D_{S C} \\
\frac{d D_{S C D}}{d t}=K_{T D} \cdot D_{S C}-\frac{2}{3} \cdot D_{S C D} \cdot K_{S C}-\frac{1}{3} \cdot D_{S C D} \cdot K_{S}-K_{T D} \cdot D_{S C D}
\end{gathered}
$$

Where $\mathrm{D}_{\mathrm{SC}}$ - total drug present at the microneedle depot in the stratum corneum, $\mathrm{K}_{\mathrm{TD}}-$ drug release rate from the encapsulated formulation, $\mathrm{D}_{\mathrm{SCD}}$ - total free drug present at the microneedle depot in the stratum corneum at time $\mathrm{t}, \mathrm{K}_{\mathrm{SC}}$ - permeability rate constant to the stratum corneum

Drug present at the microneedle depot in the viable epidermis:

$$
\frac{d D_{V E}}{d t}=K_{T D} \cdot D_{S C}-2 \times K_{T D} \cdot D_{V E}
$$




$$
\frac{d D_{V E}}{d t}=K_{T D} \cdot D_{V E}+K_{T D} \cdot D_{S C D}-\frac{2}{3} \cdot D_{V E D} \cdot K_{V E}-\frac{1}{3} \cdot D_{V E D} \cdot K_{S}-K_{T D} \cdot D_{V E}
$$

Where $\mathrm{D}_{\mathrm{VE}}$ is the total drug present at the microneedle depot in the viable epidermis at time $t$, $\mathrm{D}_{\mathrm{VED}}$ - total free drug present at the microneedle depot in the viable epidermis at time $\mathrm{t}$, $\mathrm{PC}_{\mathrm{S} / \mathrm{W}}-$ partition coefficient between skin and water, $\mathrm{K}_{\mathrm{VE}}-$ permeability rate constant to the viable epidermis, $\mathrm{K}_{\mathrm{S}}-$ permeability rate constant to the skin/hair follicles.

Drug present at the microneedle depot in the dermis:

$$
\frac{d D_{D E}}{d t}=K_{T D} \cdot D_{V E}+K_{T D} \cdot D_{V E D}-K_{T D} \cdot D_{D E}
$$

Where $\mathrm{D}_{\mathrm{DE}}$ is the total drug amount present at the microneedle depot in the dermis at time $\mathrm{t}$.

Drug permeation from the microneedle to the adjacent skin layers (33) is given by:

$$
-\frac{d M}{d t}=A \cdot P_{e} \cdot C_{b}
$$

Where $\mathrm{M}$ is the amount of drug permeating across the skin, $\mathrm{A}$ is the surface area of drug in contact with the skin, $\mathrm{P}_{\mathrm{e}}$ is the effective permeability and $\mathrm{C}_{\mathrm{b}}$ is the drug concentration at the depot site.

Drug traversing through the stratum corneum:

$$
\frac{d A_{S C}}{d t}=\frac{2}{3} \cdot D_{S C D} \cdot K_{S C}-P C_{S C / V E} \cdot A_{S C}
$$

Where $\mathrm{A}_{\mathrm{SC}}$ is the amount present in the stratum corneum at time $\mathrm{t}, \mathrm{PC}_{\mathrm{SC} / \mathrm{VE}}-$ partition coefficient between stratum corneum and viable epidermis.

Drug traversing through the viable epidermis: 


$$
\frac{d A_{V E}}{d t}=\frac{2}{3} \cdot D_{V E D} \cdot K_{V E}+K_{S C / V E} \cdot A_{S C}-A_{V E} / P C_{S / W}
$$

Where $A_{V E}$ is the amount present in the viable epidermis at time $t, D_{V E D}-$ total free drug present at the microneedle depot in the viable epidermis at time $\mathrm{t}, \mathrm{PC}_{\mathrm{S} / \mathrm{W}}-$ partition coefficient between skin and water.

Drug traversing through the hair follicles:

$$
\frac{d A_{H F}}{d t}=\frac{1}{3} \cdot D_{S C D} \cdot K_{S}+\frac{1}{3} \cdot D_{V E D} \cdot K_{S}-A_{H F} / P C_{S / W}
$$

Where $\mathrm{A}_{\mathrm{HF}}$ is the amount present in the hair follicles at time $\mathrm{t}$

Lateral diffusion from the microneedle depot was based on the drug permeability rate and the diffusion across the skin was dependent on the drug partition coefficient between the layers. Permeability rate constants $-\mathrm{K}_{\mathrm{S}}, \mathrm{K}_{\mathrm{SC}}, \mathrm{K}_{\mathrm{VE}}$ and drug partition coefficients $-\mathrm{PC}_{\mathrm{SC} / \mathrm{VE}}, \mathrm{PC}_{\mathrm{S} / \mathrm{W}}$ were derived using quantitative structure-property relationships (QSPR) informed by a previous publication (32) (included in the supplementary document). A summary of the various QSPR equations used for parameter computation is provided in the supplementary section. An average value was considered from the numerous equations.

\section{Human physiological parameters}

Key characteristics of both male and female (50:50) adults such as age ranging between 18 and 60 years, weight and body mass index (BMI) were defined initially, and other key characteristics such as body surface area (BSA) and height were computed using allometric equations. Organ weights, volumes, and blood flow rates were computed using anthropometric equations from the literature $(34,35)$. The drug distribution across tissues and organs were described using first-order differential equations $(36,37)$. Physicochemical and drug specific properties are presented in Table 1. 


\section{Model qualification}

The model was initially qualified in vivo for IM nanoformulated rilpivirine in rats followed by human data as shown in supplementary figure 1. The drug specific parameters of rilpivirine utilised in the PBPK model were qualified against available IM pharmacokinetic data followed by the qualification of the intradermal compartmental model using available in vivo data in rats from an earlier pharmacokinetic study (38). A single IM injection with two different doses - $5 \mathrm{mg} / \mathrm{kg}$ and $20 \mathrm{mg} / \mathrm{kg}$ and new in vivo experiments performed in rats with a $120 \mathrm{mg}$ intradermal microneedle patch administered for 8 weeks were used for model qualification. For the intradermal patch, only $57.45 \%$ of the total available drug was assumed to be effectively delivered over the dosing interval, i.e., the total amount of drug present in the microneedles excluding the drug present in the baseplates, as determined in previous in vivo experiments (27). PBPK models were considered as qualified if the mean simulated $\mathrm{C}_{\max }$ (maximum plasma concentration), $\mathrm{C}_{\text {trough }}$ (trough plasma concentration) and AUC (area under the curve) were within $50 \%$ of the mean reported in vivo data. Subsequently, the intradermal compartment was appended to a previously qualified rilpivirine PBPK model in humans (23) for pharmacokinetic predictions.

\section{PBPK analysis}

PBPK predictions were performed initially for a daily oral dosing for four weeks (10 mg and $25 \mathrm{mg}$ once daily for cabotegravir and rilpivirine, respectively) to reach steady-state concentrations, followed by a q4-weekly loading dose with a single microneedle patch and then 11 consecutive q4-weekly maintenance patches, for a total of 336 consecutive days of drug exposure. Pharmacokinetics were predicted for various combinations of dose (180 mg, $360 \mathrm{mg}, 540 \mathrm{mg}, 720 \mathrm{mg}, 900 \mathrm{mg}$ and $1080 \mathrm{mg})$ and release rates $\left(5 \times 10^{-4}, 1 \times 10^{-3}, 1.5 \times 10^{-3}\right.$, $2 \times 10^{-3}, 2.5 \times 10^{-3}$ and $3 \times 10^{-3} \mathrm{~h}^{-1}$ ) for both cabotegravir and rilpivirine. Considering smaller patch sizes, q-weekly MAP doses were also modelled using loading doses - 30mg, $60 \mathrm{mg}$, 
$90 \mathrm{mg}, 180 \mathrm{mg}, 270 \mathrm{mg}$ and $360 \mathrm{mg}$-- and maintenance doses - 30mg, 60mg, $90 \mathrm{mg}, 180$ $\mathrm{mg}$ and $270 \mathrm{mg}--$ at various release rates $\left(7 \times 10^{-3}, 8 \times 10^{-3}, 9 \times 10^{-3}, 10 \times 10^{-3}, 11 \times 10^{-3}\right.$ and $12 \times 10^{-3} \mathrm{~h}^{-1}$ ) after achieving steady state concentrations from oral administration. The optimal dose and release rate were identified by implementing trial and error approach by assessing various combinations of doses and release rates. Minimum doses and a range of suitable release rates of nanoformulations were estimated such that plasma concentrations remained above minimally effective concentrations throughout the dosing interval $-1.2 \mathrm{mg} / \mathrm{L}$ for a 10 $\mathrm{mg}$ daily oral $\mathrm{C}_{\text {trough }}$ for cabotegravir (39), and $70 \mathrm{ng} / \mathrm{ml}$ for a $25 \mathrm{mg}$ daily oral $\mathrm{C}_{\text {trough }}$ for rilpivirine (39).

The effect of varying penetration depth was assessed at a constant pore width of $224 \pm 5.0$ $\mu \mathrm{m}$ and varying pore radius. The effect of pore size on the release rate pharmacokinetics of rilpivirine was also assessed at a constant microneedle length of $430 \pm 6.0 \mu \mathrm{m}$ and varying pore width at a constant dose of $720 \mathrm{mg}$ and release rate of $1.5 \times 10^{-3} \mathrm{~h}^{-1}$. 


\section{Results}

\section{PBPK qualification}

Comparisons of observed and simulated pharmacokinetic parameters at the end of eight weeks are shown in Table 2. The percentage difference of the simulated $\mathrm{C}_{\max }$ and AUC against in vivo data is less than $50 \%$ for model qualification. Simulated pharmacokinetics from the designed intradermal PBPK model also satisfied the qualification limit against experimental data. Qualification of IM cabotegravir and rilpivirine human PBPK models is presented in the supplementary section.

\section{Intradermal dose and release rates}

The $\mathrm{C}_{\text {trough }}$ of cabotegravir and rilpivirine at various $\mathrm{q} 4$-weekly doses and release rates (Figure 3) and weekly intradermal loading and maintenance dose and release rates (Figure 4) are shown. Our calculations indicate that a minimum q4-weekly loading dose of $360 \mathrm{mg}$ with a release rate between $1 \times 10^{-3}-3 \times 10^{-3} \mathrm{~h}^{-1}$, and a maintenance dose of $180 \mathrm{mg}$ with a release rate of $1 \times 10^{-3}-1.5 \times 10^{-3} \mathrm{~h}^{-1}$ would be required for an intradermal cabotegravir MAP to maintain plasma concentrations above a target $C_{\text {trough }}$ of $1.2 \mu \mathrm{g} / \mathrm{ml}$.

For rilpivirine, a q4-weekly regimen requires a $1080 \mathrm{mg}$ loading dose with release rates of $1.5 \times 10^{-3}-2.5 \times 10^{-3} \mathrm{~h}^{-1}$, and a maintenance dose of $540 \mathrm{mg}$ release rates of $5 \times 10^{-4}-1 \times 10^{-3} \mathrm{~h}^{-1}$ to maintain a target $\mathrm{C}_{\text {trough }}$ of $70 \mathrm{ng} / \mathrm{ml}$.

Cabotegravir q-weekly MAP administration requires a minimum loading and maintenance dose of $60 \mathrm{mg}$ between the release rates of $7 \times 10^{-3}$ and $12 \times 10^{-3} \mathrm{~h}^{-1}$. But if the loading dose is increased to $90 \mathrm{mg}$, a maintenance dose of $30 \mathrm{mg}$ would be enough to have plasma concentrations over the target $C_{\text {trough }}$. For rilpivirine a loading dose of $270 \mathrm{mg}$ and a maintenance dose of $180 \mathrm{mg}$, with a nanoformulation release rate ranging from $7 \times 10^{-3}-$ 
$9 \times 10^{-3} \mathrm{~h}^{-1}$. This is significantly higher than the optimal release rate observed for q4-weekly formulations. However, if the loading dose is increased to $360 \mathrm{mg}$, the required maintenance dose falls to $90 \mathrm{mg}$ to sustain the required $\mathrm{C}_{\text {trough }}$. 


\section{Effect of needle length, pore radius and release rate}

The effect on pharmacokinetics of rilpivirine for varying penetration depths and needle pore sizes at a constant dose and release rate are shown in Figure 5a $\&$ b. The pharmacokinetic parameters $\mathrm{C}_{\max }$ and $\mathrm{AUC}$ increased as the penetration depth increased. However, there was no significant difference in the simulated $\mathrm{C}_{\text {trough }}$. Neither a significant difference nor a trend was observed in the pharmacokinetic parameters as the pore radius increased (Figure 5b).

Simulated intradermal administration of rilpivirine predicted a rise in $\mathrm{C}_{\max }$ as the release rate increased. However, $\mathrm{C}_{\text {trough }}$ increased until a release rate of $1.5 \times 10^{-3} \mathrm{~h}^{-1}$ and faster release rates were characterised by decreasing $\mathrm{C}_{\text {trough }}$ (Figure 6a). At a constant release rate, as the dose increased, rilpivirine pharmacokinetics increased accordingly (6b). 


\section{Discussion}

Non-invasive intradermal MAPs may represent effective novel drug delivery vehicles for chronic administration of ARVs. In this study, a compartmental PBPK model was designed and integrated with a previously published whole-body PBPK model (25). This was first qualified with observed data in rats and humans followed by informing nanoformulation characteristics in humans for cabotegravir and rilpivirine MAPs.

Model qualification against observed data showed satisfactory results with differences less than $50 \%$ in line with convention for this approach. Subsequently, the models were utilised to simulate administration of rilpivirine and cabotegravir LA formulations using MAPs. A range of release rates were evaluated to identify the optimal dosing values that would sustain plasma concentrations over established targets throughout the dosing interval at the lowest possible doses.

The simulations of cabotegravir MAPs indicate an initial minimum monthly dose of $360 \mathrm{mg}$ and a maintenance dose of $180 \mathrm{mg}$. Consequently, a MAP with high drug loading will be required. In the past, several examples of MAPs containing drug loading between 50 and $90 \%$ have been reported $(40,41)$. Additionally, in order to maximize drug loading in the needle tips, differently shaped MAPs may be used. Patches containing a higher needle density $(19 \times 19)$ while keeping the needle geometry $(600 \mu \mathrm{m}$ height and $300 \mu \mathrm{m}$ base diameter) have been previously used (42-45). These MAPs showed similar insertion depths as the $11 \times 11$ MAPs (approximately $450 \mu \mathrm{m}$ using manual insertion) (45) but have three times more needles in the same MAP area. Therefore, with drug loading of $50 \%$ to $90 \%$, the density of common polymeric materials used to prepare MAPs $\left(1.2 \mathrm{~g} / \mathrm{cm}^{3}\right)(46)$, and the volume of the needles tips, all the drug present in the needles can be successfully delivered $(40,41)$. The estimated patch size for the loading dose of cabotegravir will range between 70 
and $90 \mathrm{~cm}^{2}$ (based on a loading of $32.7 \mathrm{mg}$ of formulation per $8 \mathrm{~cm}^{2}$ ). On the other hand, the maintenance dose patch will have a size ranging from 35 to $45 \mathrm{~cm}^{2}$. Although the required patch sizes seem large, smaller patches can be achieved with higher drug loading and since these are dissolvable patches, they can be removed within a short span of time $(<24 \mathrm{~h})$ subsequent to their application.

Following a similar rationale, rilpivirine could be formulated in q-weekly patches (weekly loading and maintenance doses of $270 \mathrm{mg}$ and $180 \mathrm{mg}$, respectively). Our model suggests that the doses required for q4-weekly patches of RPV will require unrealistically large patches between $130-260 \mathrm{~cm}^{2}$. If a $19 \times 19$ RPV MAP can be prepared, the patch sizes will range between 25 and $44 \mathrm{~cm}^{2}$ for the q-weekly RPV loading dose and between 15 and $30 \mathrm{~cm}^{2}$ for the maintenance dose. High variability in dose predictions were observed due to the high variation in the abundance of cytochrome P450 enzyme across the population that affects the systemic clearance of rilpivirine.

The presented data indicate that a weekly combination CAB and RPV may be achievable for a self-administered therapy. These patch sizes seem large, but it is important to note that conventional transdermal patches with sizes up to $140 \mathrm{~cm}^{2}$ can be found in the market for post-herpetic neuralgia (47). Moreover, it has been reported that manual application of larger MAPs has been carried out successfully in human volunteers (11). However, the patient must be properly instructed as to how these patches should be applied (11). It should also be noted that the required patch size could be reduced by using more potent ARV formulations, or higher drug loading.

The parametrisation of drug partition coefficients and permeability rates between skin tissues were based on previous models, and when multiple parameters were available, an average value was selected (correlations shown in the supplementary document). However, 
standardised experimental methodology for the characterisation of these parameters and in vitro - in vivo extrapolation would support a more reliable parametrisation with application across different computational models.

Several percutaneous in silico models have been published to describe drug absorption kinetics for topical or systemic delivery. Some relevant examples include a percutaneous model for different topical formulations of diclofenac (48), as well as quantitative structurepermeation relationship (QSPR) models, porous models, transient models such as compartment models, and slow partition kinetic models, to describe transdermal drug delivery (49). Additionally, multiple pharmacokinetic dermal models for the simulation of drug permeation through the skin for topical applications have been developed (32). However, no intradermal models for the simulation of LA formulation administration using MAPs has yet been reported.

The described intradermal PBPK model provides a valuable estimate of formulation requirements for MAP delivery but is characterised by several limitations. The dose and release rates were simulated in optimal conditions and do not include any loss of drug during application. This includes the assumption of $100 \%$ bioavailability during dose predictions and lower fraction can increase the dose required thus increasing the size of the microneedle patch. A canonical shaped needle has been simulated in this study; changes in the shape and size of the microneedle such as pyramidal or tetrahedral, or an increase in microneedle density could be used to tune the release rate and diffusion following application. Ethnicity and sex are additional patient factors that can influence pharmacokinetics following intradermal administration. However, their effect on release kinetics has not been evaluated in clinical studies to date. Lag time after the application of MAPs has not been considered in this model, and a delay could be observed in the $\mathrm{C}_{\max }$ and $\mathrm{t}_{\max }$ as a consequence. The human dermis is highly vascularized, and vasodilation or vasoconstriction could lead to altered drug 
release from the depot, affecting plasma pharmacokinetics $(50,51)$. Highly lipophilic drugs and particles less than $100 \mathrm{~nm}$ tend to enter the lymphatic circulation rather than blood, which may impact pharmacokinetics (52). Drug transport proteins play a key role in defining the pharmacokinetic profile of many drugs, but limited data relating to this site of delivery restricted their inclusion in the PBPK model. Complexity in the design of nanoformulations with the estimated release rates from current technology used in this model could also prove to be a limiting factor.

The qualified intradermal PBPK model has been cross-checked only against rat data for one drug, as this was the only relevant in vivo data in the published literature. Qualification against observed human data and diverse formulations will further improve confidence in the predictive value of the model. Long-term stability and tolerability of drug formulation at the site of administration in human skin must be investigated thoroughly to prevent any unwanted side effects. Transdermal drug administration is attractive for neonatal and paediatric applications, but this model only investigated the kinetics of drug delivery in average sized adults. 


\section{Conclusion}

PBPK models have been successfully qualified for oral and IM rilpivirine and cabotegravir. A novel intradermal model has been qualified against observed data in rats and nanoformulation design has been informed for MAP administration in humans. Optimal doses between ranges of release rates suitable for intradermal delivery, and preferred dosing intervals were simulated such that plasma concentrations remained above target trough concentrations throughout dosing intervals. Based on our simulations, q4-weekly cabotegravir and q-weekly cabotegravir and rilpivirine MAPs are feasible with patch sizes less than $60 \mathrm{~cm}^{2}$, and q-monthly rilpivirine would be possible with a denser MAP. This model could provide a useful platform to inform the design of novel formulations for chronic transdermal drug administration.

\section{Acknowledgements}

This work was presented at the $25^{\text {th }}$ Conference on Retroviruses and Opportunistic Infections, Boston, MA, USA, 2018 (Poster 485)

\section{Funding}

This study was supported by the National Institute of Allergy and Infectious Diseases of the National Institutes of Health (R24 AI 118397).

\section{Transparency declarations}

Dr. Rajoli, Dr. Curley, Mr. Chiong, Dr. Larrañeta and Prof. Donnelly do not have any conflict of interests; Prof. Flexner reports grants from Gilead Sciences, personal fees from ViiV Healthcare, personal fees from Janssen Pharmaceuticals, personal fees from Merck Laboratories, personal fees from Mylan Pharmaceuticals, personal fees from Cipla 
Pharmaceuticals, outside the submitted work; In addition, Prof. Flexner has a patent SemiSolid Prodrug SDNs pending. Prof. Owen reports grants from Merck, personal fees from Merck, grants from ViiV Healthcare, personal fees from ViiV Healthcare, grants from Janssen, non-financial support from Janssen, grants from AstraZeneca, outside the submitted work; In addition, Dr. Owen has a patent drug delivery issued, and a patent drug delivery pending. Dr. Siccardi reports grants from ViiV, grants from Janssen, outside the submitted work;

\section{Author contributions}

All the authors contributed to the overall design of this study and the choice of drugs. RR designed the model, performed the simulations and analysis. RD provided the physical description of the microneedles. RR, EL and MS wrote the manuscript with the support from $\mathrm{JC}, \mathrm{CF}, \mathrm{AO}$ and $\mathrm{RD}$. All the authors contributed towards the writing and reviewing of the final manuscript. 


\section{References}

1. Zhang H, Jin R, Yao C, Zhang T, Wang M, Xia W, et al. Combination of long-acting HIV fusion inhibitor albuvirtide and LPV/r showed potent efficacy in HIV-1 patients. AIDS Research and Therapy. 2016;13(1):8. doi:10.1186/s12981-016-0091-1.

2. Claborn KR, Meier E, Miller MB, Leffingwell TR. A Systematic Review of Treatment Fatigue among HIV-infected Patients Prescribed Antiretroviral Therapy. Psychology, health \& medicine. 2015;20(3):255-65. doi:10.1080/13548506.2014.945601.

3. Landovitz RJ, Kofron R, McCauley M. The promise and pitfalls of long-acting injectable agents for HIV prevention. Current Opinion in HIV and AIDS. 2016;11(1):122-8. doi:10.1097/coh.0000000000000219.

4. Trezza C, Ford SL, Spreen W, Pan R, Piscitelli S. Formulation and pharmacology of long-acting cabotegravir. Curr Opin HIV AIDS. 2015;10(4):239-45. doi:10.1097/coh.0000000000000168.

5. Barnhart M. Long-Acting HIV Treatment and Prevention: Closer to the Threshold. Global Health: Science and Practice. 2017;5(2):182-7. doi:10.9745/ghsp-d-17-00206.

6. Taddio A, Ipp M, Thivakaran S, Jamal A, Parikh C, Smart S, et al. Survey of the prevalence of immunization non-compliance due to needle fears in children and adults. Vaccine. 2012;30(32):4807-12. doi:10.1016/j.vaccine.2012.05.011.

7. Parsons JT, Rendina HJ, Whitfield THF, Grov C. Familiarity with and Preferences for Oral and LongActing Injectable HIV Pre-exposure Prophylaxis (PrEP) in a National Sample of Gay and Bisexual Men in the U.S. AIDS and Behavior. 2016;20(7):1390-9. doi:10.1007/s10461-016-1370-5.

8. Williams J, Sayles HR, Meza JL, Sayre P, Sandkovsky U, Gendelman HE, et al. Long-acting parenteral nanoformulated antiretroviral therapy: interest and attitudes of HIV-infected patients. Nanomedicine. 2013;8(11):1807-13. doi:10.2217/nnm.12.214.

9. Meyers K, Rodriguez K, Moeller RW, Gratch I, Markowitz M, Halkitis PN. High Interest in a LongActing Injectable Formulation of Pre-Exposure Prophylaxis for HIV in Young Men Who Have Sex with Men in NYC: A P18 Cohort Substudy. PLOS ONE. 2014;9(12):e114700. doi:10.1371/journal.pone.0114700.

10. Donnelly RF, Larrañeta E. Microarray patches: potentially useful delivery systems for long-acting nanosuspensions. Drug Discovery Today. 2018;23(5):1026-33. doi:10.1016/j.drudis.2017.10.013.

11. Ripolin A, Quinn J, Larrañeta E, Vicente-Perez EM, Barry J, Donnelly RF. Successful application of large microneedle patches by human volunteers. International Journal of Pharmaceutics. 2017;521(1-2):92-101. doi:10.1016/j.ijpharm.2017.02.011.

12. Donnelly RF, Singh TRR, Garland MJ, Migalska K, Majithiya R, McCrudden CM, et al. HydrogelForming Microneedle Arrays for Enhanced Transdermal Drug Delivery. Advanced Functional Materials. 2012;22(23):4879-90. doi:10.1002/adfm.201200864.

13. Ita K. Transdermal Delivery of Drugs with Microneedles_Potential and Challenges. Pharmaceutics. 2015;7(3):90-105. doi:10.3390/pharmaceutics7030090.

14. Bakshi RP, Tatham LM, Savage AC, Tripathi AK, Mlambo G, Ippolito MM, et al. Long-acting injectable atovaquone nanomedicines for malaria prophylaxis. Nature Communications. 2018;9(1):315. doi:10.1038/s41467-017-02603-z. 
15. Tatham LM, Savage AC, Dwyer A, Siccardi M, Scott T, Vourvahis M, et al. Towards a Maraviroc Long-Acting Injectable Nanoformulation. European Journal of Pharmaceutics and Biopharmaceutics. 2018. doi:10.1016/j.ejpb.2018.04.009.

16. Aoyagi S, Izumi H, Isono Y, Fukuda M, Ogawa H. Laser fabrication of high aspect ratio thin holes on biodegradable polymer and its application to a microneedle. Sensors and Actuators A: Physical. 2007;139(1):293-302. doi:10.1016/j.sna.2006.11.022.

17. Ling M-H, Chen M-C. Dissolving polymer microneedle patches for rapid and efficient transdermal delivery of insulin to diabetic rats. Acta Biomaterialia. 2013;9(11):8952-61. doi:10.1016/j.actbio.2013.06.029. 18. Ding Z, Verbaan FJ, Bivas-Benita M, Bungener L, Huckriede A, van den Berg DJ, et al. Microneedle arrays for the transcutaneous immunization of diphtheria and influenza in BALB/c mice. Journal of Controlled Release. 2009;136(1):71-8. doi:10.1016/j.jconrel.2009.01.025.

19. Prausnitz MR, Langer R. Transdermal drug delivery. Nature Biotechnology. 2008;26:1261-8. doi:10.1038/nbt.1504.

20. Kim M, Jung B, Park J-H. Hydrogel swelling as a trigger to release biodegradable polymer microneedles in skin. Biomaterials. 2012;33(2):668-78. doi:10.1016/j.biomaterials.2011.09.074.

21. Yang P-Y, Zou H, Chao E, Sherwood L, Nunez V, Keeney M, et al. Engineering a long-acting, potent GLP-1 analog for microstructure-based transdermal delivery. Proceedings of the National Academy of Sciences. 2016;113(15):4140-5. doi:10.1073/pnas.1601653113.

22. Chen W, Tian R, Xu C, Yung BC, Wang G, Liu Y, et al. Microneedle-array patches loaded with dual mineralized protein/peptide particles for type 2 diabetes therapy. Nature Communications. 2017;8(1):1777. doi:10.1038/s41467-017-01764-1.

23. Rajoli RKR, Back DJ, Rannard S, Meyers CF, Flexner C, Owen A, et al. In Silico Dose Prediction for Long-Acting Rilpivirine and Cabotegravir Administration to Children and Adolescents. Clin Pharmacokinet. 2018;57(2):255-66. doi:10.1007/s40262-017-0557-X.

24. Yoshida K, Budha N, Jin JY. Impact of Physiologically Based Pharmacokinetic Models on Regulatory Reviews and Product Labels: Frequent Utilization in the Field of Oncology. Clinical Pharmacology \& Therapeutics. 2017;101(5):597-602. doi:10.1002/cpt.622.

25. Rajoli RKR, Back DJ, Rannard S, Freel Meyers CL, Flexner C, Owen A, et al. Physiologically Based Pharmacokinetic Modelling to Inform Development of Intramuscular Long-Acting Nanoformulations for HIV. Clin Pharmacokinet. 2015;54(6):639-50. doi:10.1007/s40262-014-0227-1.

26. Nestorov I. Whole Body Pharmacokinetic Models. Clin Pharmacokinet. 2003;42(10):883-908. doi:10.2165/00003088-200342100-00002.

27. Garland MJ, Migalska K, Tuan-Mahmood T-M, Raghu Raj Singh T, Majithija R, Caffarel-Salvador E, et al. Influence of skin model on in vitro performance of drug-loaded soluble microneedle arrays. International Journal of Pharmaceutics. 2012;434(1):80-9. doi:10.1016/j.ijpharm.2012.05.069.

28. Böhling A, Bielfeldt S, Himmelmann A, Keskin M, Wilhelm KP. Comparison of the stratum corneum thickness measured in vivo with confocal Raman spectroscopy and confocal reflectance microscopy. Skin Research and Technology. 2014;20(1):50-7. doi:10.1111/srt.12082. 
29. Sandby-Moller J, Poulsen T, Wulf HC. Epidermal thickness at different body sites: Relationship to age, gender, pigmentation, blood content, skin type and smoking habits. Acta Dermato-Venereologica. 2003;83(6):410-3. doi:10.1080/00015550310015419.

30. Ronald A. Bergman AKA, Paul M. Heidger Jr. Atlas of Microscopic Anatomy - A Functional Approach. . 2nd edition ed: W B Saunders Co 1999.

31. Ibrahim R, Nitsche JM, Kasting GB. Dermal Clearance Model for Epidermal Bioavailability Calculations. Journal of Pharmaceutical Sciences. 2012;101(6):2094-108. doi:10.1002/jps.23106.

32. Gajewska M, Worth A, Urani C, Briesen H, Schramm KW. Application of physiologically-based toxicokinetic modelling in oral-to-dermal extrapolation of threshold doses of cosmetic ingredients. Toxicology Letters. 2014;227(3):189-202. doi:10.1016/j.toxlet.2014.03.013.

33. Sinko PJ, Leesman GD, Amidon GL. Predicting Fraction Dose Absorbed in Humans Using a Macroscopic Mass Balance Approach. Pharmaceutical Research. 1991;8(8):979-88. doi:10.1023/a:1015892621261.

34. Bosgra S, Eijkeren Jv, Bos P, Zeilmaker M, Slob W. An improved model to predict physiologically based model parameters and their inter-individual variability from anthropometry. Crit Rev Toxicol. 2012;42(9):751-67. doi:10.3109/10408444.2012.709225.

35. Williams LR. Reference values for total blood volume and cardiac output in humans. 1994. Available from: http://web.ornl.gov/info/reports/1994/3445606042010.pdf. Accessed: 18/01/2018.

36. Peters S. Evaluation of a Generic Physiologically Based Pharmacokinetic Model for Lineshape Analysis. Clin Pharmacokinet. 2008;47(4):261-75. doi:10.2165/00003088-200847040-00004.

37. Poulin P, Theil FP. Prediction of pharmacokinetics prior to in vivo studies. 1. Mechanism-based prediction of volume of distribution. J Pharm Sci. 2002;91(1):129-56. https://doi.org/10.1002/jps.10005. 38. van 't Klooster G, Hoeben E, Borghys H, Looszova A, Bouche M-P, van Velsen F, et al. Pharmacokinetics and Disposition of Rilpivirine (TMC278) Nanosuspension as a Long-Acting Injectable Antiretroviral Formulation. Antimicrobial Agents Chemotherapy. 2010;54(5):2042-50. https://doi.org/10.1128/aac.01529-09.

39. Margolis DA, Gonzalez-Garcia J, Stellbrink H-J, Eron JJ, Yazdanpanah Y, Podzamczer D, et al. Longacting intramuscular cabotegravir and rilpivirine in adults with HIV-1 infection (LATTE-2): 96-week results of a randomised, open-label, phase 2b, non-inferiority trial. Lancet. 2017;390(10101):1499-510. doi:10.1016/S0140-6736(17)31917-7.

40. McCrudden MTC, Alkilani AZ, McCrudden CM, McAlister E, McCarthy HO, Woolfson AD, et al. Design and physicochemical characterisation of novel dissolving polymeric microneedle arrays for transdermal delivery of high dose, low molecular weight drugs. Journal of Controlled Release. 2014;180:71-80. doi:10.1016/j.jconrel.2014.02.007.

41. González-Vázquez P, Larrañeta E, McCrudden MTC, Jarrahian C, Rein-Weston A, Quintanar-Solares $\mathrm{M}$, et al. Transdermal delivery of gentamicin using dissolving microneedle arrays for potential treatment of neonatal sepsis. Journal of Controlled Release. 2017;265:30-40. doi:10.1016/j.jconrel.2017.07.032.

42. Larrañeta E, Lutton REM, Brady AJ, M.Vicente-Pérez E, David WA, Singh TRR, et al. Microwave-Assisted Preparation of Hydrogel-Forming Microneedle Arrays for Transdermal Drug Delivery Applications. Macromolecular Materials and Engineering. 2015;300(6):586-95. doi:10.1002/mame.201500016. 
43. Kennedy J, Larrañeta E, McCrudden MTC, McCrudden CM, Brady AJ, Fallows SJ, et al. In vivo studies investigating biodistribution of nanoparticle-encapsulated rhodamine B delivered via dissolving microneedles. Journal of Controlled Release. 2017;265:57-65. doi:10.1016/j.jconrel.2017.04.022.

44. Vicente-Perez EM, Larrañeta E, McCrudden MTC, Kissenpfennig A, Hegarty S, McCarthy HO, et al. Repeat application of microneedles does not alter skin appearance or barrier function and causes no measurable disturbance of serum biomarkers of infection, inflammation or immunity in mice in vivo. European Journal of Pharmaceutics and Biopharmaceutics. 2017;117:400-7. doi:10.1016/j.ejpb.2017.04.029.

45. Donnelly RF, McCrudden MTC, Zaid Alkilani A, Larrañeta E, McAlister E, Courtenay AJ, et al. Hydrogel-Forming Microneedles Prepared from "Super Swelling” Polymers Combined with Lyophilised Wafers for Transdermal Drug Delivery. PLOS ONE. 2014;9(10):e111547. doi:10.1371/journal.pone.0111547. 46. Parekh G, Pattekari P, Joshi C, Shutava T, DeCoster M, Levchenko T, et al. Layer-by-layer nanoencapsulation of camptothecin with improved activity. International Journal of Pharmaceutics. 2014;465(1):218-27. doi:10.1016/j.ijpharm.2014.01.041.

47. Prausnitz MR, Mitragotri S, Langer R. Current status and future potential of transdermal drug delivery. Nature Reviews Drug Discovery. 2004;3:115-24. doi:10.1038/nrd1304.

48. Polak S, Ghobadi C, Mishra H, Ahamadi M, Patel N, Jamei M, et al. Prediction of concentration \& time profile and its inter-individual variability following the dermal drug absorption. Journal of Pharmaceutical Sciences. 2012;101(7):2584-95. doi:10.1002/jps.23155.

49. Mitragotri S, Anissimov YG, Bunge AL, Frasch HF, Guy RH, Hadgraft J, et al. Mathematical models of skin permeability: An overview. International Journal of Pharmaceutics. 2011;418(1):115-29. doi:10.1016/j.ijpharm.2011.02.023.

50. Sugibayashi K, Yanagimoto G, Hayashi T, Seki T, Juni K, Morimoto Y. Analysis of skin disposition of flurbiprofen after topical application in hairless rats. Journal of Controlled Release. 1999;62(1):193-200. doi:10.1016/S0168-3659(99)00038-3.

51. Ita KB. Transdermal drug delivery: progress and challenges. Journal of Drug Delivery Science and Technology. 2014;24(3):245-50. doi:10.1016/S1773-2247(14)50041-X.

52. Tegenge M, Mitkus R. A physiologically-based pharmacokinetic (PBPK) model of squalenecontaining adjuvant in human vaccines. J Pharmacokinet Pharmacodyn. 2013;40(5):545-56. doi:10.1007/s10928-013-9328-y.

53. Clinical Pharmacology and Biopharmaceutics Review(s). Application number: 202022Orig1s000. Center for Drug Evaluation and Research, 2011. Available from: http://www.accessdata.fda.gov/drugsatfda_docs/nda/2011/202022Orig1s000ClinPharmR.pdf. Accessed: 17/07/2018. 


\section{Table captions}

Table 1. Physicochemical properties, in vitro and population pharmacokinetic data of antiHIV drugs

Table 2. Validation of the PBPK model for IM (38) and intradermal rilpivirine formulations in rats in vivo 


\section{Figure captions}

Figure 1. Drug release pathway from the microneedles in the intradermal compartment reaching the blood and lymphatic circulation. $\mathrm{A}_{\mathrm{HF}}, \mathrm{A}_{\mathrm{SC}}, \mathrm{A}_{\mathrm{VE}}$ - drug amount penetrating the hair follicles, stratum corneum and viable epidermis respectively; $\mathrm{D}_{\mathrm{DE}}, \mathrm{D}_{\mathrm{SC}}, \mathrm{D}_{\mathrm{VE}}-$ microneedle drug depot in the dermis, stratum corneum and viable epidermis respectively; $\mathrm{D}_{\mathrm{SCD}}, \mathrm{D}_{\mathrm{VED}}$ - amount of released drug from the nanoparticles in the stratum corneum and viable epidermis respectively; $\mathrm{K}_{\mathrm{s}}, \mathrm{K}_{\mathrm{SC}}, \mathrm{K}_{\mathrm{VE}}$ - rate of drug permeation from microneedle to skin, microneedle to stratum corneum and microneedle to viable epidermis respectively; $\mathrm{K}_{\mathrm{TD}}$ - drug release rate from the encapsulated nanoparticles; $\mathrm{PC}_{\mathrm{SC} / \mathrm{VE}}, \mathrm{PC}_{\mathrm{S} / \mathrm{W}}-$ drug partition coefficient between stratum corneum \& viable epidermis and skin \& water respectively.

Figure 2. Representative drug deposition subsequent to microneedle insertion in different layers of the skin at time $\mathrm{t}=0 \mathrm{~h}$ for varying insertion depths. $\mathrm{L}$ - microneedle insertion depth, $\mathrm{r}$ - radius of the created pore; $\mathrm{D}_{\mathrm{SC}}, \mathrm{D}_{\mathrm{VE}}, \mathrm{D}_{\mathrm{DE}}$ - amount of drug present in stratum corneum, viable epidermis and dermis respectively.

Figure 3. $C_{\text {trough }}$ values of cabotegravir $(a, b)$ and rilpivirine $(c, d)$ - 4-weekly loading $(a, c)$ and maintenance $(b, d)$ doses for various release rates. The red lines represent the target concentrations considered for this dose optimisation study. LD - loading dose, PO - once daily. Error bars represent the standard deviation.

Figure 4. $C_{\text {trough }}$ values of cabotegravir $(a, b)$ and rilpivirine $(c, d)$ - weekly loading $(a, c)$ and maintenance $(b, d)$ doses for various release rates. The red lines represent the target concentrations considered for this dose optimisation study. LD - loading dose. Error bars represent the standard deviation.

Figure 5. Pharmacokinetic parameters $A U C, C_{\max }$ and $C_{\text {trough }}$ of rilpivirine for various (a) penetration depths and (b) microneedle pore radius. Error bars represent the standard deviation.

Figure 6. Effect on plasma concentration of rilpivirine at (a) various release rates in $\mathrm{h}^{-1}$ at a constant dose of $720 \mathrm{mg}$ and (b) varying doses at a constant release rate of $1.5 \times 10^{-3} \mathrm{~h}^{-1}$. 


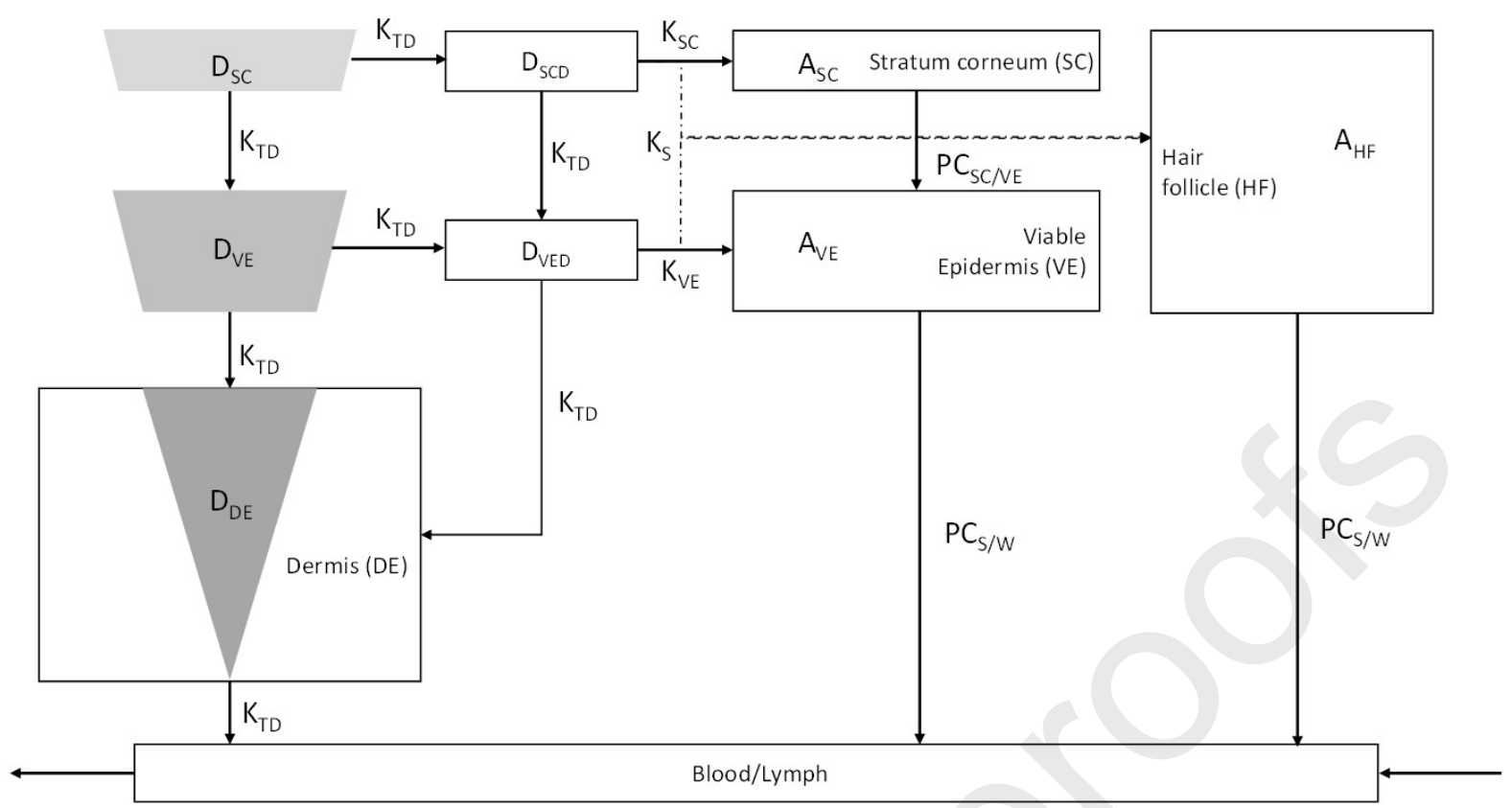

\begin{tabular}{|c|c|c|c|c|}
\hline \multirow{2}{*}{$\begin{array}{l}\text { Stratum } \\
\text { corneum (SC) } \\
\text { Viable } \\
\text { Epidermis (VE) }\end{array}$} & \multirow{2}{*}{$\begin{array}{c}D_{S C} \\
D_{V E}\end{array}$} & \multicolumn{3}{|l|}{ For $r=187.5 \mu \mathrm{m}$} \\
\hline & & & $\mathrm{L}=375 \mu \mathrm{m}$ & $\mathrm{L}=600 \mu \mathrm{m}$ \\
\hline \multirow{4}{*}{ Dermis (DE) } & & $\%$ of $\mathrm{MN}$ in $\mathrm{D}_{\mathrm{SC}}$ & 12.3 & 7.8 \\
\hline & & $\%$ of $M N$ in $D_{V E}$ & 43.7 & 27.5 \\
\hline & & $\%$ of $M N$ in $D_{D E}$ & 44 & 64.7 \\
\hline & & Total volume (\%) & 100 & 100 \\
\hline
\end{tabular}


a)

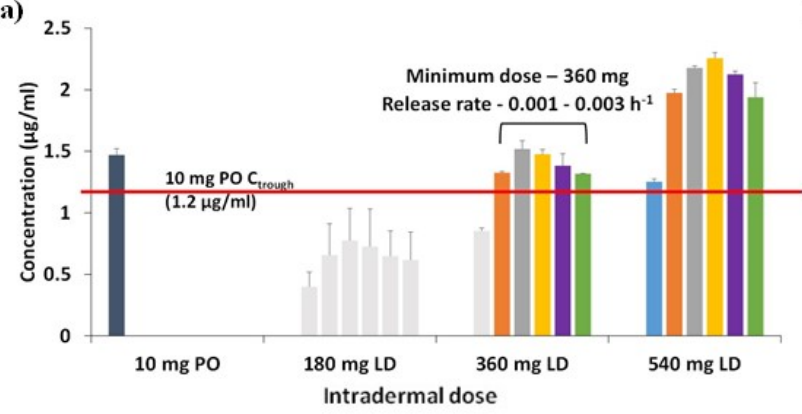

$=10 \mathrm{mg}$ PO $=0.0005=0.001 \quad 0.0015=0.002 \quad 0.0025=0.003$

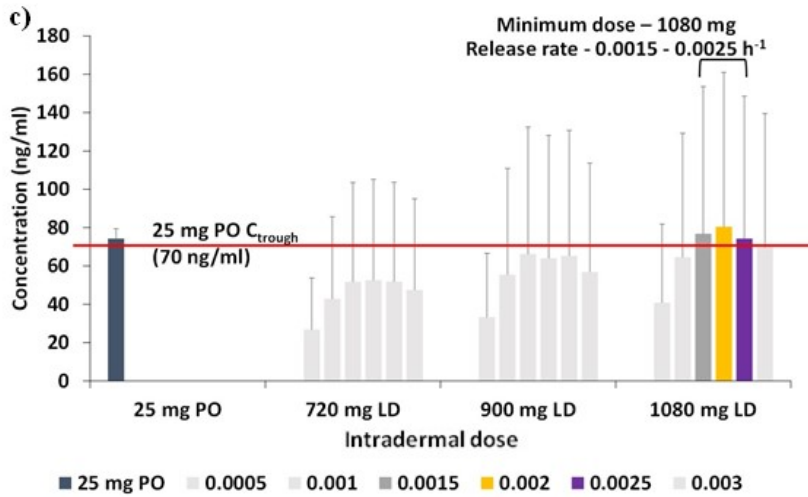

b)

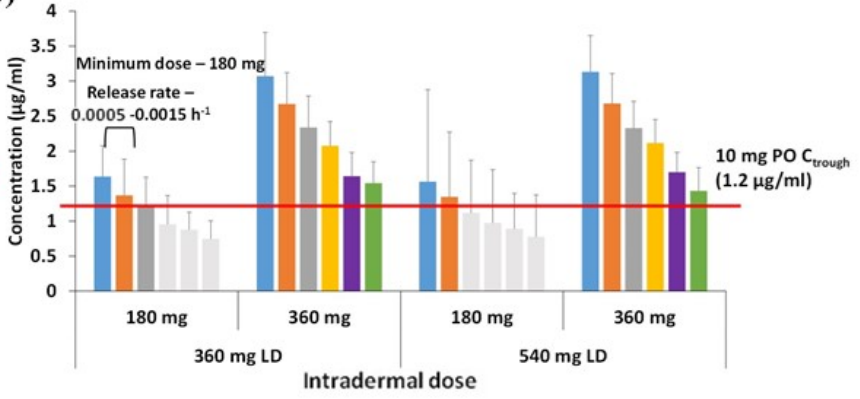

$=0.0005=0.001=0.0015=0.002=0.0025=0.003$

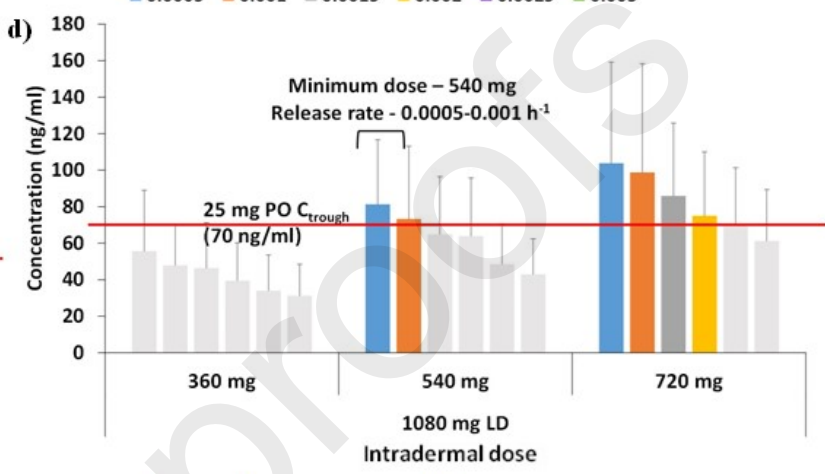

$=0.0005=0.001=0.0015=0.002 \quad 0.0025 \quad 0.003$ 
(a)
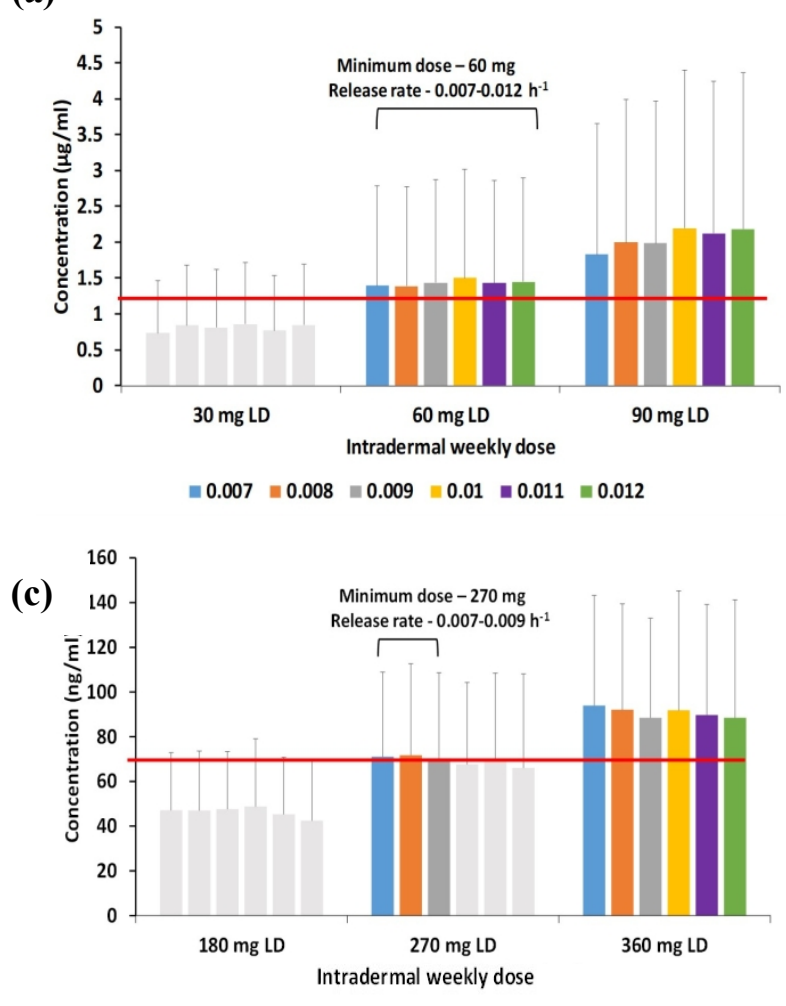

$=0.007=0.008=0.009=0.01 \backsim 0.011=0.012$ (b)
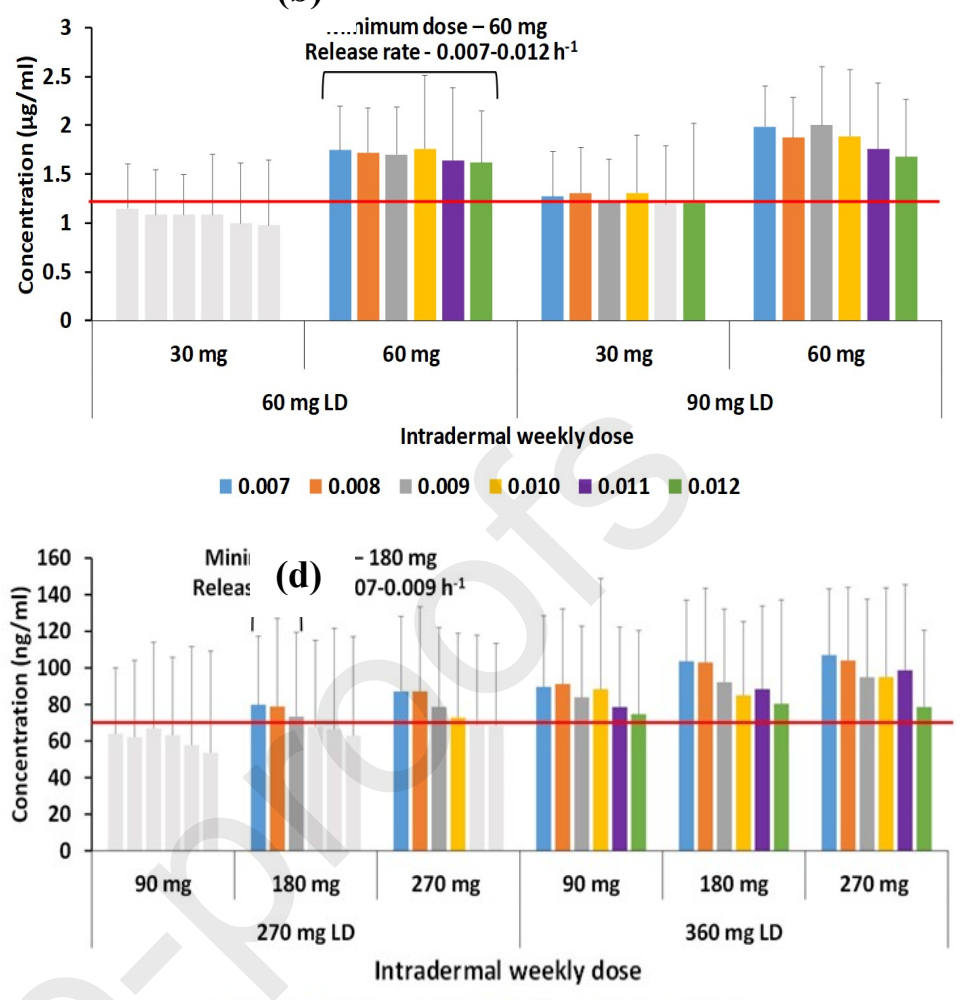

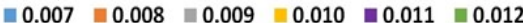


(a)

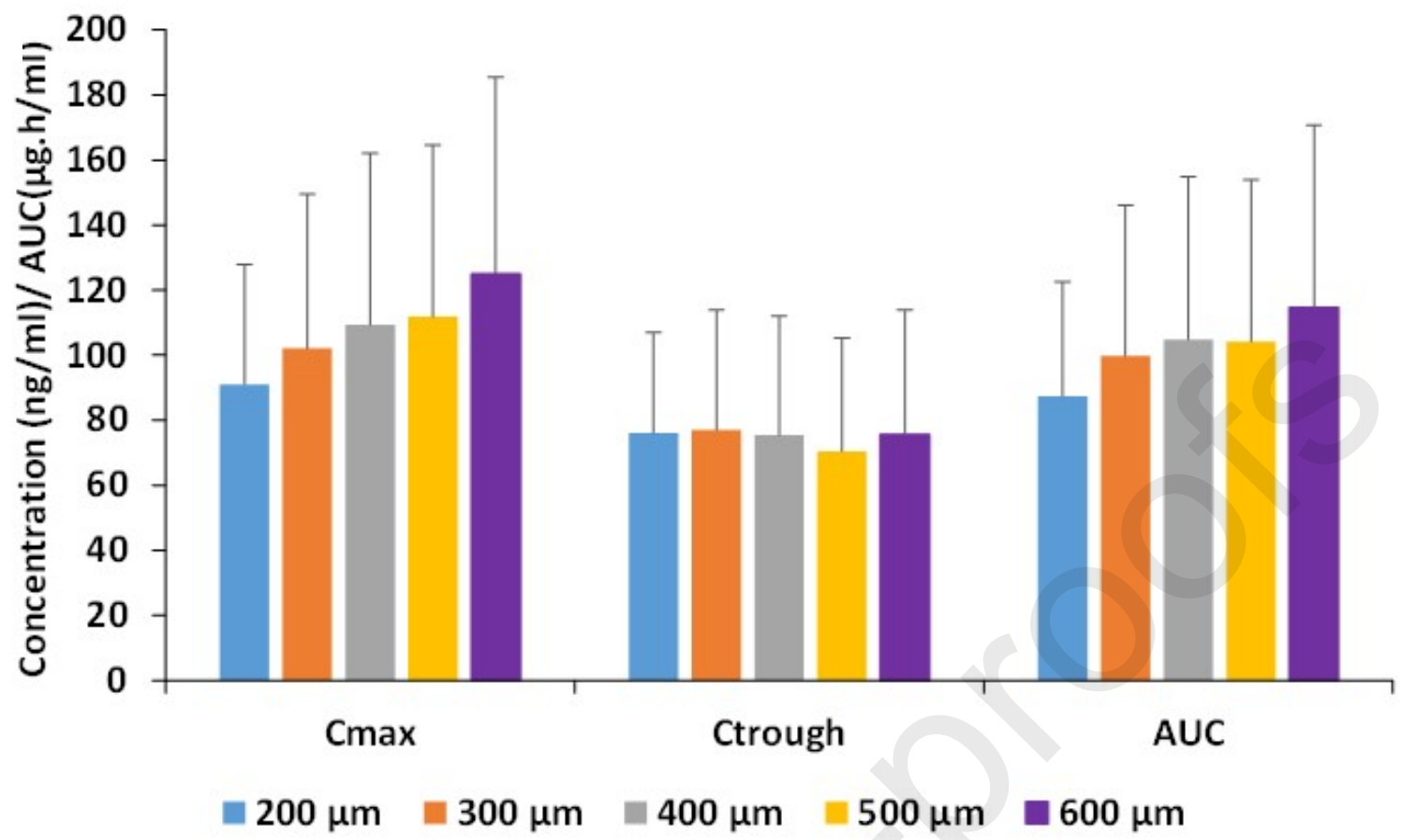

(b)

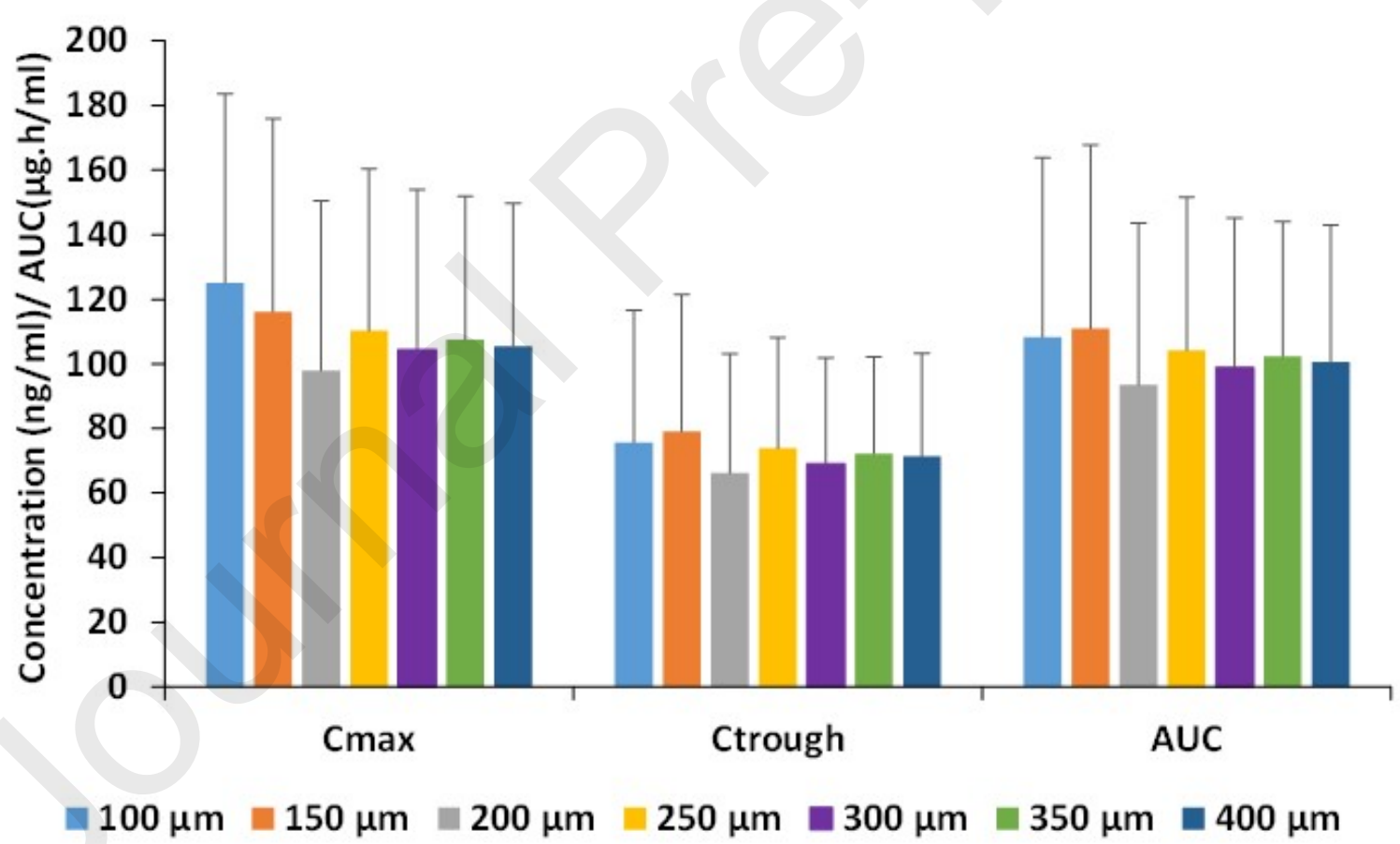


(a)

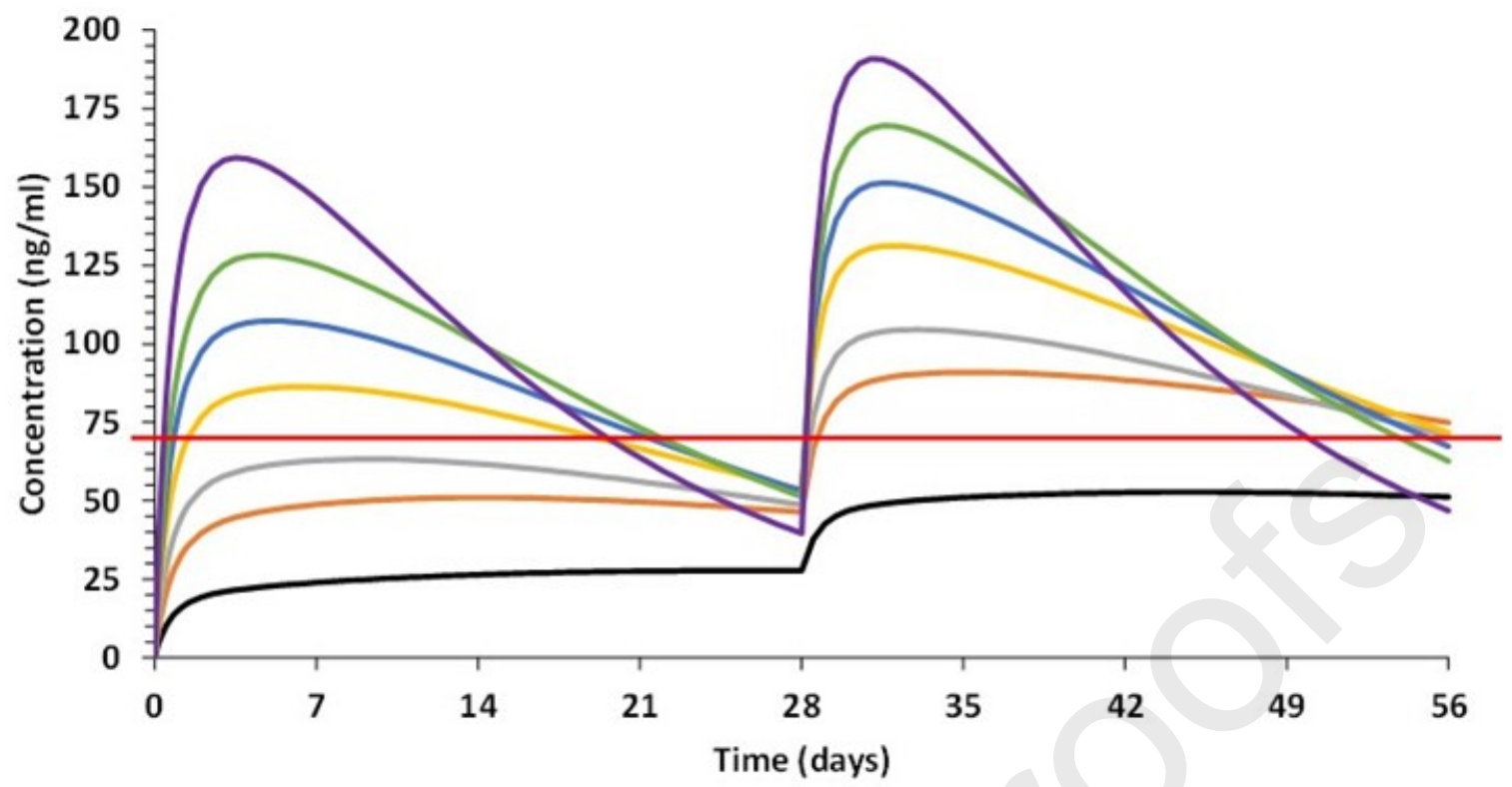

(b)

$$
-0.0005
$$

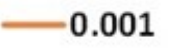

$0.0015-0.002$

$-0.0025$

$-0.003$

$-0.004$

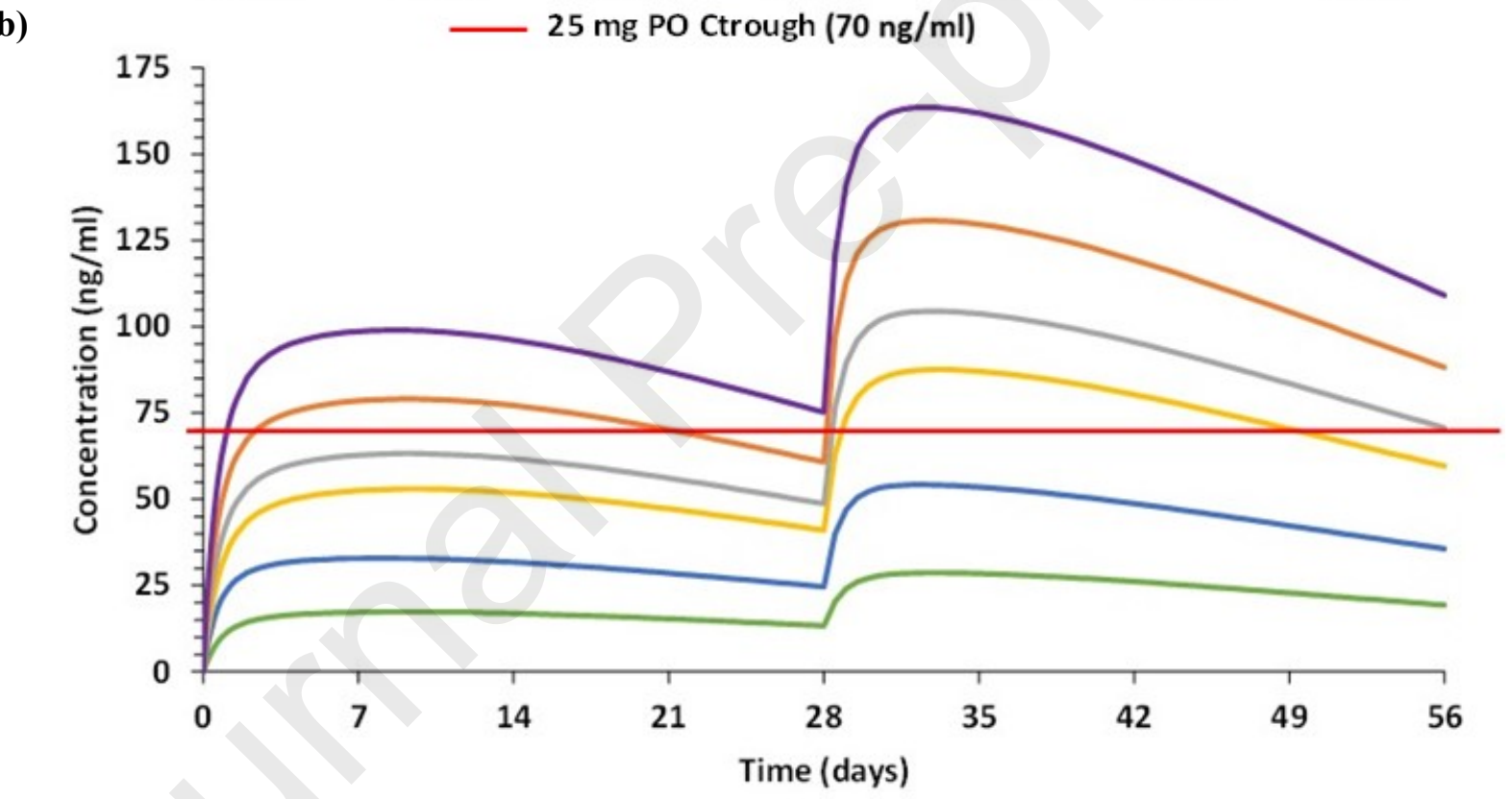

$-180 \mathrm{mg}-360 \mathrm{mg}-540 \mathrm{mg}-720 \mathrm{mg}-900 \mathrm{mg}-1080 \mathrm{mg}$ $25 \mathrm{mg}$ PO Ctrough $(70 \mathrm{ng} / \mathrm{ml})$ 


\begin{tabular}{|c|c|c|c|}
\hline & Rilpivirine (rat) & Rilpivirine (human) & Cabotegravir (human) \\
\hline $\log \mathbf{P}_{\text {o:w }}$ & $4.32(53)$ & $4.32(53)$ & $2.2(23)$ \\
\hline Protein binding & $99.7 \%(53)$ & $99.7 \%(53)$ & $99.3 \%(23)$ \\
\hline $\mathbf{p K}_{\mathrm{a}}$ & $3.26(53)$ & $3.26(53)$ & $4.14(23)$ \\
\hline Blood-to-plasma ratio & $0.67(53)$ & $0.67(53)$ & $0.441(23)$ \\
\hline & & & $\uparrow 4.5(1 \mathrm{~A} 1) / 2.2$ (1A9) \\
\hline Plasma clearance & $1.3 \mathrm{~L} / \mathrm{kg} / \mathrm{h}$ & $\dagger 2.04(53)$ & (23) \\
\hline IM release rate $\left(h^{-1}\right)$ & $2.6 \times 10^{-2}$ & ${ }^{*} 9 \times 10^{-4}$ & $4.54 \times 10^{-4}(23)$ \\
\hline Intradermal release rate & & & - \\
\hline$\left(h^{-1}\right)$ & $\$ 2 \times 10^{-4}$ & & \\
\hline Dose & $5,20 \mathrm{mg} / \mathrm{kg} \mathrm{IM}, 120 \mathrm{mg}$ TD & - & - \\
\hline
\end{tabular}

Values are presented as mean (reference). $\log \mathrm{P}_{\mathrm{o}: \mathrm{w}}-$ Partition coefficient between octanol and water; $\mathrm{pKa}-$ logarithmic value of the dissociation constant; *Release rate followed a linear increase with respect to time shown in the following equation: $(0.005 / 1344) *$ time +0.0002 , time in hours. ${ }^{\prime}$ Values represent intrinsic clearance in $\mu 1 / \mathrm{min} / \mathrm{pmol}$, rilpivirine is metabolised by CYP3A4, and cabotegravir by UGT1A1 and UGT1A9. ${ }^{*}$ Release rate observed for an old formulation of rilpivirine derived using the PBPK model (38). 


\begin{tabular}{|c|c|c|c|c|c|c|c|c|c|}
\hline \multirow[b]{2}{*}{$\begin{array}{c}\text { Route of } \\
\text { administration and } \\
\text { dose }\end{array}$} & \multicolumn{2}{|c|}{ Observed } & \multicolumn{4}{|c|}{ Simulated $(n=100)$} & \multicolumn{3}{|c|}{$\begin{array}{c}\text { \% difference } \\
\text { simulated vs. clinical }\end{array}$} \\
\hline & $\mathrm{C}_{\max }$ & $\mathbf{A} \mathbf{U} \mathbf{C}_{0 \text {-last }}$ & $\mathrm{C}_{\text {trough }}$ & $\mathrm{C}_{\max }$ & $\mathbf{A U} \mathbf{C}_{0 \text {-last }}$ & $\mathrm{C}_{\text {trough }}$ & $\mathrm{C}_{\max }$ & $\mathbf{A U} \mathbf{C}_{0 \text {-last }}$ & $\mathrm{C}_{\text {trough }}$ \\
\hline $\begin{array}{l}\text { Intramuscular } \\
(5 \mathrm{mg} / \mathrm{kg}, \text { single } \\
\text { injection })\end{array}$ & 71 & 3840 & - & $\begin{array}{r}55.9 \pm \\
6.43\end{array}$ & $\begin{array}{r}5.67 \pm \\
1.25\end{array}$ & - & -21.3 & 47.6 & - \\
\hline $\begin{array}{l}\text { Intramuscular } \\
(20 \mathrm{mg} / \mathrm{kg} \text {, single } \\
\text { injection) }\end{array}$ & 158 & 15300 & - & $\begin{array}{r}222 \pm \\
25.5\end{array}$ & $\begin{array}{r}22.4 \pm \\
4.64\end{array}$ & - & 40.5 & 46.3 & - \\
\hline $\begin{array}{l}\text { Intradermal } \\
\uparrow(120 \mathrm{mg}, \text { microneedle } \\
\text { patch })\end{array}$ & 416 & - & 26.5 & $\begin{array}{r}481 \pm \\
42.9\end{array}$ & $\begin{array}{r}286 \pm \\
28.1\end{array}$ & $\begin{array}{r}38.7 \pm \\
4.45\end{array}$ & 24.5 & & 46.0 \\
\hline
\end{tabular}

Values are represented as arithmetic mean \pm standard deviation wherever applicable; $\mathrm{AUC}_{0 \text {-last }}-$ area under the concentration-time curve, $\mathrm{C}_{\max }-$ maximum plasma concentration, $\mathrm{C}_{\text {trough }}-$ trough plasma concentration; $\mathrm{C}_{\max }$ and $\mathrm{C}_{\text {trough }}$ are expressed as $\mathrm{ng} / \mathrm{ml}$ and AUC is expressed as $\mu \mathrm{g} \times \mathrm{h} / \mathrm{ml}$; * PBPK model is assumed to be qualified if $\%$ difference is less than $100 .^{\dagger}$ Only $57.45 \%$ of the total administered drug was assumed to be delivered using microneedles (27). 


\section{Journal Pre-proofs}

Intradermal PBPK compartmental model

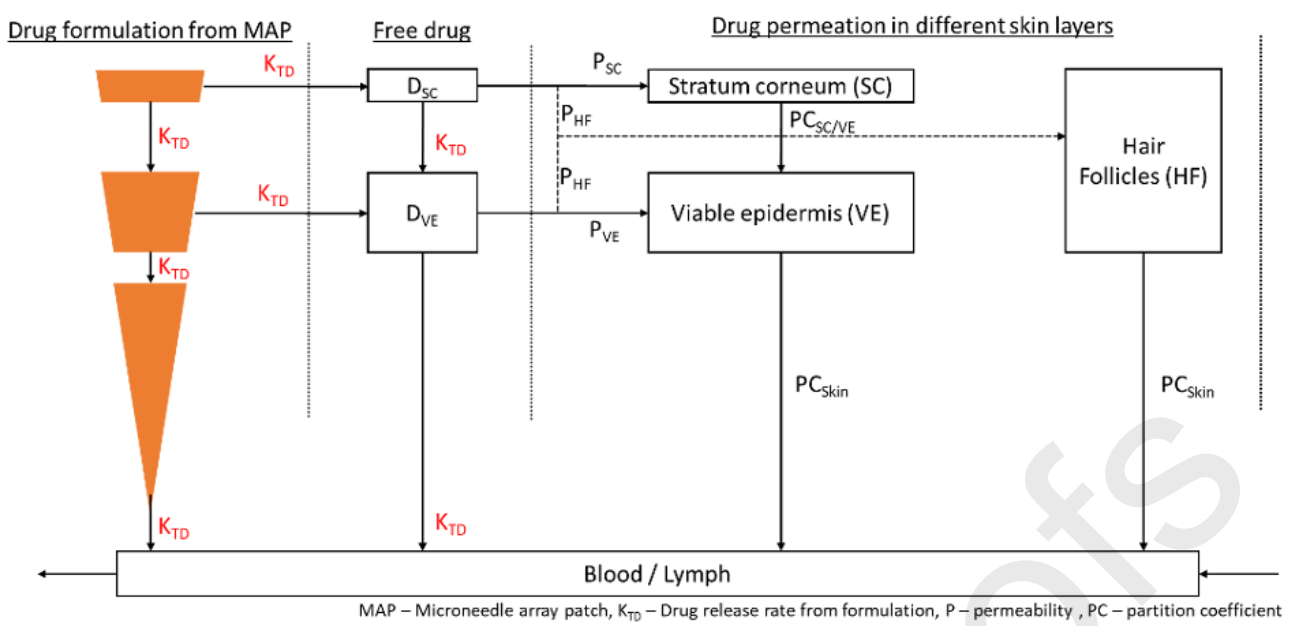

